\title{
LA FALACIA NATURALISTA. RESPUESTAS PARA UNA FUNDAMENTACIÓN DEL DERECHO NATURAL. LOS ARGUMENTOS DE J. FINNIS Y M. BEUCHOT
}

\author{
Javier SALDAÑA SERRANO
}

\section{Resumen:}

El autor analiza los fundamentos del derecho natural a partir de los argumentos expuestos por John Finnis y Mauricio Beuchot, quienes defienden la postura iusnaturalista. La idea del trabajo es discutir la crítica de la "falacia naturalista" y las respuestas que desarrollan estos autores como fundamento del derecho natural.

\begin{abstract}
:
The author analyzes some basic foundations of natural law theory discussed in the works of John Finnis and Mauricio Beuchot, the main issue addressed is the responses and defense that these authors have developed against the "naturalistic fallacy" objection, responses and defense that constitute the author argues a foundation for natural law theory.
\end{abstract}


SUMARIO: I. Planteamiento del problema. II. Los argumentos de John Finnis. III. Los argumentos de Mauricio Beuchot. IV. Conclusión. V. Bibliografía.

\section{Planteamiento Del PRoblema}

Uno de los argumentos recurrentemente citados a la hora de oponerse a la ética y filosofia del derecho de inspiración iusnaturalista es la llamada falacia naturalista (naturalistic fallacy). Los más importantes pensadores de corte iuspositivista, y en general todos aquellos teóricos que se inscriben en un no cognitivismo ético, lo han esgrimido como uno de los recursos más importantes y eficaces contra la "extraña" figura del derecho natural. En uno y otro sentido todos los críticos del derecho natural han empleado este argumento para descalificarlo. Sirva un botón como muestra:

Nadie puede negar que la afirmación de que "algo es" —esto es, el enunciado con el cual se describe un hecho real-, es esencialmente diferente del enunciado que dice que "algo debe producirse", esto es: del enunciado con el cual se describe una norma; y que, en consecuencia, de que algo exista no puede seguirse que algo deba existir, de igual modo a que de que algo deba ser, no puede seguirse, que algo sea. ${ }^{1}$

Esta afirmación hecha por el profesor Hans Kelsen tiene la virtualidad de ser especialmente cautivadora y atrayente quizá por la sencillez misma de su presentación. Sin embargo, ¿qué es lo que se contiene detrás de esta afirmación?, ¿qué es exactamente lo que encierra?, ¿cuáles son los efectos prácticos a los que conduciría la aceptación de la misma? La respuesta a las anteriores interrogantes puede ser enunciada igualmente en forma sencilla. La tesis enunciada plantea la distinción entre realidad y valor, entre naturaleza y sociedad, o, para utilizar los mismos términos del profesor vienés, la incomunicabilidad entre causalidad e imputación.

1 Kelsen, H., Teoría pura del derecho, México, Porrúa-UNAM, 1991, p. 19. 
En esta tesis se alude a dos mundos, el del "ser", o de la naturaleza, y el del "deber ser", propio del comportamiento humano. Ahora bien, ¿es verdad tal incomunicabilidad?, ¿es verdad que ambos mundos se presentan no sólo como diferentes sino como absolutamente separados?

La respuesta a las interrogantes anteriores debe ser ubicada en sus justas dimensiones. Una primera aproximación nos tiene que llevar a aceptar que Kelsen tenía razón, esto es, que es verdad que hay una separación entre realidad y valor, y que una cosa es la causalidad y otra la imputación. Sin embargo, esta afirmación sólo puede ser aceptada si se comienza, como lo hace Kelsen, comprendiendo al "ser" como empíricamente perceptible, lo fáctico, lo no tendencial. Sólo así es posible reconocer tal aseveración como evidente y aceptable. Es claro que el "deber ser" del derecho no puede deducirse del "ser" puramente fáctico de lo acaecido en sociedad. Habría sin duda un salto lógico inadmisible. Sin embargo, ¿es este el "ser" que explica el derecho natural defendido por Aristóteles y Tomás de Aquino? Un conocimiento profundo de esta corriente de pensamiento rechazaria que el "ser" sea comprendido tal y como lo presenta Kelsen y el resto de los críticos del derecho natural. El "ser" de la metafísica realista se comprende de diferente manera, no como un puro dato fáctico, como lo puro dado.

Aunque Kelsen cita a Moore como argumento de autoridad para justificar su afirmación, la idea de la inderivabilidad del "deber" a partir del "es" ha sido también atribuida al filósofo escocés David Hume, quien en su Treatise of Human Nature expone la tesis central del argumento. La controversial cita es la siguiente:

En todo sistema moral de que haya tenido noticia, hasta ahora, he podido siempre observar que el autor sigue durante cierto tiempo el modo de hablar ordinario, estableciendo la existencia de Dios o realizando observaciones sobre los quehaceres humanos, y, de pronto, me encuentro con la sorpresa de que, en vez de las cópulas habituales de las proposiciones: es y no es, no veo ninguna proposición que no esté 
conectada con un debe o un no debe. Este cambio es imperceptible, pero resulta, sin embargo, de la mayor importancia. En efecto, en cuanto que este debe o no debe expresa alguna nueva relación o afirmación, es necesario que ésta sea observada y explicada y que al mismo tiempo se dé razón de algo que parece absolutamente inconcebible, a saber: cómo es posible que esta nueva relación se deduzca de otras totalmente diferentes. Pero como los autores no usan por lo común de esta precaución, me atreveré a recomendarla a los lectores: estoy seguro de que una pequeña reflexión sobre esto subvertiria todos los sistemas corrientes de moralidad, haciéndonos ver que la distinción entre vicio y virtud, ni está basada meramente en relaciones de objetos, ni es percibida por la razón. ${ }^{2}$

Este pasaje sin duda es significativo, y aunque el mismo ha sido uno de los más discutidos y controvertidos de la ética de Hume, hoy ya no consigue la atención que mereció en otros momentos. Podriamos decir que, sin ser un asunto olvidado, ya no se gastan en éste las energías de otros tiempos. Sin embargo, y a pesar de lo anterior, se suelen aún encontrar fuertes críticas al derecho natural formuladas desde la trinchera de la inderivabilidad del debe a partir del

2 En este escrito se usará la versión castellana de la obra: Hume, D., Tratado de la naturaleza humana, edición preparada por F. Duque, Madrid, Tecnos, 1998, pp. 633 y 634. En lengua inglesa el texto referido es el siguiente: "I cannot forbear adding to these reasoning an observation, which may, perhaps, be found of some importance. In every system of morality, which I have hitherto met with, I have always remark'd, that the author proceeds for some time in the ordinary way of reasoning, and establishes the being of Good, or makes observations concerning human affairs; when of a sudden I am surpriz'd to find, that instead of the usual copulations of propositions, is, and is not, I meet with no proposition that is not connected with an ough, or an ought not. This change is imperceptible; but is, however, of the last consequence. For as this ought, or ought not, expresses some new relation or affirmation, 'tis necessary that it shou'd be observ'd and explain'd; an at the same time that a reason should be given, for what seems altogether inconceivable, how this new relation can be a deduction from others, which are entirely different from it. But as authors do not commonly use this precaution, I shall presume to recommend it to the readers; and am persuaded, that this small attention wou'd subvert all the vulgar systems of morality, and let us see, that the distinction of vice and virtue is nor founded merely on the relations of objects, nor is perceiv'd by reason". Hume, D., Treatise of Human Nature, L.A., Selby-Bigge, M. A., Oxford, 1960, pp. 469 y 470. 
es o de la reformulada falacia naturalista, sobre todo en aquellas culturas juridicas con fuerte raigambre normativista como la mexicana. Es por eso que he creído conveniente referirme en este trabajo a los argumentos que presentan dos filósofos prácticos de reconocido prestigio para oponerse a las críticas contra el derecho natural, haciendo ver que dichas formulaciones están muy lejos de alcanzar a la tradición del realismo metafísico, particularmente, al derecho natural de raigambre aristotélico-tomista.

Los autores referidos son el filósofo australiano John Finnis y el mexicano Mauricio Beuchot. Ambos ofrecen, con una técnica argumentativa rigurosa y original, las tesis centrales de la tradición clásica.

\section{LOS ARGUMENTOS DE JOHN FINNIS}

Finnis, profesor de la Universidad de Oxford es, junto con Germain Grisez, Joseph Boyle y Robert P. George, uno de los más importantes representantes de la denominada New School of Natural Law, ${ }^{3}$ escuela que haciendo suyos los argumentos centrales del derecho natural clásico en la versión de Aristóteles y Tomás de Aquino, formula una relectura de los mismos en diálogo con el pensamiento anglosajón, específicamente con la tradición analitica del derecho defendida por autores como Hart o Raz.

Uno de los asuntos más controvertidos del profesor Finnis, y que ha generado una fuerte polémica incluso al interior de la propia tradición aristotélico-tomista, ha sido justamente el de la derivación ilícita del "deber ser" a partir del "ser", tema que ha tratado en diversos trabajos ${ }^{4}$ pero cuya

3 Para una visión general de la New School of Natural Law, cfr. Massini, C., I., "The new school of natural law. Some approaches", Rechtstheorie, 30, Berlin, 1999, pp. 461-468.

4 Cfr. Finnis., J., "Natural law and the "is"-"ought" question: an invitation to Professor Veatch", The Catholic Lawyer, 26/4, 1981, pp. 266-277. Cfr. "Natural Inclinations and Natural Rights: Deriving "Ought" from "is" According to Aquinas", en L. J. Elders-K. Hedwig (eds.), Lex et libertas. Freedom and Law According to St. Thomas Aquinas, Citta del Vaticano, Pontificia Academia di S. Tommaso, Librería Editrice Vaticana, 1987. 
más completa exposición se encuentra en su obra principal Natural Law and Natural Rights, ${ }^{5}$ la que sin duda "ha servido de puente entre una teoría moral de inspiración clásica - aunque renovada- y las filosofias jurídicas y morales contrarias". 6

La tesis central de la que parte Finnis es aceptar el error lógico que denuncia Hume, esto es, el error de inferir proposiciones deónticas a partir de proposiciones ónticas, de deducir el debe (proposiciones valorativas o normativas), a partir del es (proposiciones de hecho o avalorativas).

\section{Hume como punto de partida en el razonamiento de John Finnis}

El texto con el que Finnis inicia su exposición es el párrafo de Hume, ya transcrito, que ya se ha hecho célebre en el debate sobre la famosa "ley de Hume". Según Finnis, dos son las interpretaciones más relevantes del texto referido. La primera de ellas apunta a que Hume está enunciando una verdad lógica: que de un conjunto de premisas no morales, o no valorativas, no se puede seguir una conclusión moral o valorativa. ${ }^{7}$ Así, no es posible aceptar que en la conclusión se encuentren razones para la acción si al menos en alguna de las premisas no se encuentran éstas.

La segunda interpretación es que tal cita habría que ubicarla en el exacto contexto histórico en el que Hume la escribió, ya que el pensador escocés la elaboró como un ataque contra los pensadores racionalistas del siglo XVIII, específicamente contra Samuel Clarke, como uno de sus más importantes representantes. “...un ataque cuya pieza central es la tesis de que la percepción racional de las cua-

5 Finnis, J., Natural law and Natural Rights, Oxford, Claredon Press, 1980. Hay una versión castellana de este libro por Orrego C., Ley natural y derechos naturales, Buenos Aires, Abeledo-Perrot, 2000. Esta versión es la que utilizaremos, en adelante $L N D N$.

6 Orrego, C., "Estudio preeliminar", en $L N D N$, cit., nota 5, p. 16.

7 Cfr. LNDN, cit., nota 5, p. 70. 
lidades morales de las acciones no podría proporcionar por sí misma una orientación que mueva a la acción". ${ }^{8}$ De cualquier modo y en ambos supuestos, Finnis reconoce que el principio enunciado por Hume ha de reconocerse como verdadero y significativo. ${ }^{9}$

Un primer punto importante destacado por Finnis, es el hecho de establecer que Hume no es el primer autor que formula esta tesis, pues ya se encontraba en Platón, Aristóteles y Tomás de Aquino. Más aún, Hume incurrió en la falacia que según la interpretación tradicional él había denunciado: "Si no fuese por el hecho de que Hume ofrece como propias cuatro o cinco opiniones incongruentes sobre la naturaleza y la base de las proposiciones morales (véase el cuidadoso análisis en Jonathan Harrison, Hume's Moral Epistemology $)^{10}$ yo tendría que añadir que el mismo Hume transgrede notoriamente el principio de que el "deber" no puede derivarse del "ser". ${ }^{11}$

Como se puede desprender del texto de Hume y las interpretaciones que sobre el mismo se han hecho, el pensador escocés negó a la razón toda posibilidad de un conocimiento sobre la moral. Para él, sólo existió un tipo de racionalidad, la teórica o especulativa, la cual se encontraba distante de los sentimientos y de las sensaciones que producian la moral, ignorando con esto la existencia de una racionalidad práctica, y con ello la idea fundamental de "bien" como motivo para la acción humana.12 Para Hume, por tanto, no existe una razón práctica normativa que oriente el obrar humano a la consecución del bien. Él, deja para el obrar humano sólo un cierto tipo de racionalidad de carácter instrumental: la razón es solamente un

8 Ibidem, pp. 70 y 71.

9 Cfr. idem.

10 Harrison, Jonathan, Hume's Moral Epistemology, Oxford, 1976, pp. 110-25.

11 Idem.

12 Cfr. Soaje Ramos, G., "John Finnis y el derecho natural", Anuario de filosofía jurídica y social, 7, Buenos Aires, 1987, pp. 82 y 83. 
instrumento para conseguir fines fijados de manera subracional.

De este modo, y ya dentro del ámbito del derecho, el paralogismo lógico enunciado por Hume ha sido considerado por los autores positivistas como central en su debate contra el derecho natural. Sin embargo, para Finnis, y en este punto me parece especialmente claro y preciso, ningún autor iusnaturalista de importancia ha afirmado que el derecho positivo derive lógicamente de la naturaleza empírica ni que se deduzca sin más del derecho natural. Esto es, que el "deber ser" de la norma positiva se derive del "ser" de las cosas o del "ser" del derecho natural (el cual es una forma de "deber ser"), o que deba ser una copia de éste. Del mismo modo, Finnis niega que la ley natural sostenga que los seres humanos están dedicados o unidos en comunidad de objetivos como, por ejemplo, la búsqueda de la justicia. ${ }^{13}$

El argumento desde el que Finnis objeta éstas y otras críticas que se le formulan al derecho natural es que los principales autores iusnaturalistas, esto es, tanto Aristóteles como Tomás de Aquino, admitirian sin dificultad que el deber no puede deducirse del ser, ${ }^{14}$ pues estos pensadores aceptaron sin ninguna objeción la diferencia entre la razón especulativa y la razón práctica, ambas con sus respectivos principios, evidentes por sí mismos y que sirven como puntos de partida en ambos razonamientos.

\section{Razonamiento especulativo y práctico}

El punto enunciado es uno de los tres argumentos a señalar en la controversia del error lógico de inferir el "debe" del "es" en John Finnis, es decir, el reconocimiento y aceptación de la especial distinción entre razón especulativa y práctica. Para el profesor oxonienese, igual que como para toda la tradición clásica, ambos tipos de razonamiento par-

13 Cfr. LNDN, cit., nota 5, p. 63.

14 Cfr. ibidem, p. 80. 
ten de principios básicos, que son tales porque desde ellos se comienzan a elaborar sus argumentos. Estos principios reciben justamente el nombre de principios especulativos y prácticos en atención a esa diferenciación. Finnis pondrá de manera especial su atención en los segundos, estableciendo que éstos expresan nuestra comprensión de un valor que puede proporcionar el punto de partida para razonar qué hacer. Así, por ejemplo, el "conocimiento es algo bueno que vale la pena poseer", o "estar bien informado y con la mente clara es una buena forma de ser", éstos son principios de la razonabilidad práctica. ${ }^{15}$

Para ejemplificar lo señalado anteriormente, Finnis explica en términos lógicos, especificamente a través del silogismo práctico, el ejemplo del conocimiento y de cómo aquí no existe una inferencia ilícita del "debe" a partir del "es".

(1) "Sería bueno averiguar la verdad sobre los supuestos principios de la ley natural";

(2) "Es probable que la lectura crítica de este libro me ayude a averiguar lo que quiero averiguar sobre estas materias";

(3) "Luego, a pesar de lo aburrido que es, lo leeré por completo y reflexionaré sobre sus argumentos".

Aquí, la primera de sus premisas se encuentra expresada a modo de un principio práctico, refleja un deseo inteligente al "referir su objeto (averiguar sobre la ley natural) a la forma inteligible y general de bien de la cual dicho objeto es una forma posible de participación o ejemplificación". ${ }^{16} \mathrm{La}$ segunda de las premisas es un juicio de hecho sobre el libro, $y$, finalmente, la conclusión expresa el curso de actuación a seguir. De este modo, el principio de razonamiento práctico actuaría como el punto de arranque desde el cual el hombre comprende que su actuación tiene un fin al cual dirige su comportamiento. No siendo una regla, el principio sirve para

15 Cfr. ibidem, p. 94.

16 Ibidem, p. 95. 
orientar nuestro razonamiento, y "puede concretarse (más que "aplicarse") en un gran número indefinido de premisas y principios prácticos más específicos”. 17

\section{El argumento de la naturaleza humana}

Ubicado ya en el plano del razonamiento práctico, Finnis expondrá el segundo argumento importante en la polémica de la inderivabilidad del "debe" a partir del "es". Este es el de la naturaleza humana, argumento que probablemente sea el más controvertido y objetado, incluso por quienes se inscriben dentro de la corriente aristotélico-tomista. ${ }^{18}$ Con las particularidades de cada uno de los pensadores críticos, se puede decir que la objeción central a la propuesta de Finnis, igual que a la de Grisez y su continuadores, sería que la tesis de estos autores "adolece de fallas en la interrelación de la razón práctica sistemática con una filosofia de la naturaleza"19 (Hittinger); o que la misma sustituye una compresión ontológica por una deontológica de la ley natural y en consecuencia presenta una "ley natural que no toma en cuenta la naturaleza"20 excusando el argumento metafísico de las proposiciones morales (Lloyd Weinreb), o como lo señala uno de sus más importantes ob-

17 Idem. Lo que Finnis señala acerca del razonamiento práctico sobre la "concreción" de éste, se entiende muy bien en el caso del Derecho. Sobre este punto Andrés Ollero ha insistido desde siempre en la importancia de comprender la denominada "aplicación del Derecho", más como "concreción" o "determinación" que como "derivación". Cfr. Ollero, A., ¿Tiene razón el derecho? Entre método científico y voluntad política, Madrid, Congreso de los Diputados, 1996, pp. 435-445, especialmente, p. 441. En sentido análogo, Serna, P., "Hermenéutica y relativismo", De la argumentación a la hermenéutica, Granada, Comares, 2003, pp. 4-7 y 216-218.

18 Un resumen de las objeciones al referido argumento por seguidores de las tesis aristotélicas-tomistas en George R., P., "Ley natural y naturaleza humana", Boletín Mexicano de Derecho Comparado, 110, México, 2004, pp. 598-601. Cfr. tb., Massini, C., I., "Razón práctica y objetividad del derecho. El debate contemporáneo acerca de los principios jurídicos”, Sapientia, LIX., fas. 215, Buenos Aires, 2004, p. 229.

19 George R., P., "Ley natural y naturaleza humana”, Boletin Mexicano de Derecho Comparado, cit., nota 18, p. 598.

20 Ibidem, p. 599. 
jetores, Henry Veatch, al señalar que Grisez y con él Finnis, erigen "una pared separando la razón práctica de la teórica, la ética de la metafísica, la naturaleza de la moral, el "ser" del "deber ser"". 21

¿Cuál es el razonamiento base que sirve a estos autores para formular dichas objeciones? Sin duda, una ética "fuerte" se alcanza a través del recurso a la naturaleza humana como dato antecedente a la prescripción. Según ellos, sin el recurso y apelación a la naturaleza humana y en definitiva a la metafísica que revela hechos propios de tal naturaleza, no se ve cómo sea posible fundar una ética sólida. De este modo y para estos autores, no hay ningún proceso indebido de inderivabilidad en el recurso antecedente a la naturaleza humana, porque la propia naturaleza contiene ya una fuerte carga deóntica, es decir, en el propio "ser" de tal naturaleza existe ya latente el "deber ser".

Finnis y Grisez se oponen a la afirmación anterior explicando que ésta incurre en la falacia naturalista, es decir, establece proposiciones deónticas de proposiciones ónticas. Para ellos y sus seguidores, ninguna conclusión que establezca razones para la acción puede estar fundada en premisas que no contenga razones para la acción.

En primer lugar, habrá que decir que Finnis acepta la existencia de la naturaleza humana, es decir, él jamás ha negado la existencia de tal naturaleza, no sólo eso sino que además en el plano puramente ontológico, no epistemológico, la bondad de los bienes humanos depende de la naturaleza; sin embargo, el conocimiento de ésta no es a priori o exterior. En este punto Finnis es especialmente claro: para él la naturaleza humana se conoce desde dentro, desde su vital ejercicio, sin necesidad de una deducción metafísica. Aquí, la razonabilidad práctica de la persona se funda en unos primeros principios, los cuales son inderivados y se caracterizan por tener por objeto solamente bienes humanos básicos. Estos principios son los más básicos y funda-

21 Veatch, H., "Natural Law and the Is-Ought Question", Catholic Lawyer, 26, 1981, p. 265, citado por ibidem. 
mentales en sí mismos, son las razones más básicas para la acción y como tales no derivan de nada.

El conocimiento práctico (es el caso de las disciplinas normativas), es tal desde sus primeros principios, evidentes, no inferidos de principios especulativos. Estos primeros principios, afirma Finnis:

No son inferidos de proposiciones metafísicas sobre la naturaleza humana, o sobre la naturaleza del bien y del mal, o sobre la "función de un ser humano", ni son inferidos de una concepción teleológica de la naturaleza ni de ninguna otra concepción de la naturaleza. No son inferidos o derivados de nada. ${ }^{22}$

Con lo anterior, Finnis intenta salir de la acusación formulada contra la teoría del derecho natural, según la cual, ésta pretende inferir deberes a partir de hechos, haciendo ver que en el caso del razonamiento práctico, que es el caso de la acción humana, no se parte de un conocimiento especulativo o metafísico de la naturaleza humana conocida previamente. Resulta especialmente contundente la afirmación que hace al respecto cuando establece que:

..."si la naturaleza del hombre fuese diferente, también los serian sus deberes". Las formas básicas del bien captadas por el entendimiento práctico son lo que es bueno para los seres humanos con la naturaleza que tienen. Tomás de Aquino piensa que el razonamiento práctico no comienza comprendiendo esta naturaleza como desde fuera, mediante observaciones y juicios psicológicos, antropológicos o metafisicos, que definan la naturaleza humana, sino experimentando la propia naturaleza, por decirlo así, desde adentro, bajo la forma de las propias inclinaciones. ${ }^{23}$

Según lo que se acaba de exponer, la idea que Finnis tiene del razonamiento práctico parte de la praxis vital del hombre, donde se conocen ciertos bienes básicos que deben

22 LNDN, cit., nota 5, p. 67.

23 Ibidem, pp. 67 y 68. 
ser realizados de acuerdo con lo establecido por el primer principio de la razón práctica (bonum faciendum et prosequendum, malum vitandum) y con los restantes requerimientos de razonabilidad práctica. Tales bienes forman parte de la naturaleza metafísica del hombre pero su conocimiento práctico no deriva del conocimiento especulativo o metafisico de esa naturaleza.

Ahora bien, ya en el plano epistemológico, ¿cómo accede la inteligencia humana al conocimiento de tales principios? En este punto Finnis es especialmente claro al establecer que las razones más básicas de la acción humana son conocidas por evidencia. No siendo inferidos de nada, tales principios son autoevidentes. En realidad, en este punto, Finnis está interpretando el conocido texto de Tomás de Aquino (I-II q. 94. a. 2) que enuncia esta tesis: “...los principios de la ley natural son en el orden práctico lo que los primeros principios de la demostración en el orden especulativo, pues unos y otros son evidentes por sí mismos". ${ }^{24}$

Rober P. George, seguidor de esta corriente y quien mejor ha comprendido esta posición tanto de Grisez como de Finnis, ha resumido muy bien el problema del conocimiento de los primeros principios del siguiente modo:

Se conocen por actos no inferenciales de comprensión en los cuales aprehendemos objetivos o propósitos como valederos en sí mismos. Las razones más básicas para la acción son aquellas cuya intelegibilidad no depende de razones más profundas o aun más fundamentales. Como razones básicas no pueden ser derivadas ya que no existe nada más fundamental que pudiera servir como premisa para una derivación lógica. De modo que deben ser autoevidentes. ${ }^{25}$

Los argumentos anteriores son ilustrativos y demuestran con toda claridad como Finnis acepta que el paso del ser al deber es indebido; después coloca su argumentación al ni731.

24 Tomas de Aquino, Summa Theologiae, I-II, q, 94. a. 2., Madrid, BAC, 1997, p.

25 George R., P., "Ley natural y naturaleza humana”, Boletín mexicano de derecho Comparado, cit., nota 18, p. 603. 
vel del puro razonamiento práctico, o en términos lógicos, se ubica sólo en el silogismo práctico, rechazando expresamente cualquier recurso a un nivel antropológico o metafisico previo. ${ }^{26}$ Esto no significa, como lo hemos dicho antes, que Finnis rechace la idea de naturaleza humana, pero aún reconociéndola y fundando en ella los bienes en el plano ontológico, no deriva de ella los principios básicos para la acción humana en el plano práctico. Finnis acepta dicha idea y reconoce igualmente el argumento metafísico que explica al hombre, pero rechaza que de ésta se deriven las acciones básicas de realización humana.

Ahora bien, ¿qué quiere decir el profesor oxoniense cuando afirma que Tomás de Aquino acude a la naturaleza humana experimentándola desde dentro "bajo la forma de las propias inclinaciones"? Finnis, en este punto, está pensando en la afirmación de Tomas de Aquino establecida en renglones precedentes cuando reconoce que "el bien es lo primero que se alcanza por la aprehensión de la razón práctica, ordenada a la operación; porque todo agente obra por un fin, y el fin tiene razón de bien". ${ }^{27} \mathrm{El}$ bien, por tanto, se alcanza por las inclinaciones naturales del hombre, por la manera y forma en la que éstas lo aprehenden. Por el modo de lograrlas. "Por otra parte, como el bien tiene razón de fin, y el mal, de lo contrario, síguese que todo aquello a lo que el hombre se siente naturalmente inclinado lo aprehende la razón como bueno y, por ende, como algo que debe ser procurado, mientras que su contrario lo aprehende como mal y como vitando". 28

Lo que Finnis pretende significar es que, en la teoría de Tomás de Aquino, y en la suya propia, lo percibido como bueno, como bien, que debe hacerse y alcanzarse, se pre-

26 Cfr. Finnis., J., Fundamentals of Ethics, Londres, Georgetown University Press, 1983, p. 22. Un análisis de la visión de la ética no metafísica que Finnis sostiene pude verse en la reseña que escribe Soaje Ramos, G., "Sobre Fundamentals of Ethics", Ethos, 14-15, Buenos Aires, 1986-1987, pp. 236 y ss. 732.

27 Tomas de Aquino, Summa Theologiae, I-II, q, 94. a. 2., ed., cit., nota 24, p.

28 Idem. 
senta de manera inmediata y autoevidente a la conciencia humana. Así, por ejemplo, bienes como el conocimiento (la verdad buscada por sí misma) o la preservación de la vida, (cada uno de los aspectos de la vitalidad) son bienes para el hombre "que han de ser buscados". Y como el principio primero de la razón práctica es "el bien hay que hacerlo y perseguirlo, y el mal evitarlo", el conocimiento o la preservación de la vida deben ser buscados y perseguidos. No hay aquí ningún concepto de naturaleza humana especulativo a partir del cual se obtenga o se derive que hay que conservar la vida o el conocimiento. Ambos bienes, por contrario, son comprendidos como tales en virtud de la propia inclinación natural del hombre.

Por otra parte, habrá que insistir en que dichas inclinaciones naturales en el hombre están medidas por la racionalidad. Así, concluye Finnis, siguiendo a Tomás de Aquino: "El criterio de conformidad o contrariedad respecto de la naturaleza humana es la razonabilidad". ${ }^{29}$ En definitiva, en la acción humana, lo correcto moralmente y su contrario, no son inferidos de una noción a priori de naturaleza humana, sino de lo que es razonable moralmente en orden a la consecución o preservación de un bien. Finnis lo deja claramente establecido al señalar que para el Aquinate descubrir qué es lo correcto o incorrecto no es preguntarse por si está o no de acuerdo con la naturaleza del hombre, sino si tal acción es o no razonable. ${ }^{30}$

4. Bienes humanos básicos y principios de razonabilidad práctica

Por haber explicado ya los dos argumentos más importantes del pensamiento de Finnis para oponerse a la temida falacia naturalista, sólo señalaré, en términos generales, una distinción que considero importante a efectos de comprender mejor lo antes expuesto.

29 LNDN, cit., nota 5, p. 69.

30 Cfr. idem. 
En la teoría cuyas lineas generales se acaban de mostrar desempeñan una función esencial los siguientes argumentos: por una parte, el primer principio de la razón práctica y los bienes básicos, y, por otra, los requerimientos o principios inderivados de la razonabilidad práctica. Aquellos son de naturaleza premoral; estos últimos son los que convierten en morales las decisiones, porque, si son seguidos, las acciones serán razonables, y si no son respetados, serán irrazonables.

La distinción entre bienes premorales y bienes morales apuntada por Finnis es especialmente importante porque dicha distinción le servirá para reconocer que el primer principio del razonamiento práctico (se debe obrar y perseguir el bien y evitar el mal), y los bienes básicos que enuncia, son premorales, porque apuntan, como señala Orrego, "a bienes humanos que son objeto tanto de las elecciones buenas como de las malas". ${ }^{31}$ Así, primero conocemos los bienes premolares, y una vez elegidos los bienes a conseguir, estando conformes con todas las exigencias de razonabilidad práctica, dirigimos nuestra acción a la consecución de los mismos. Es en esta última parte donde ya nos encontramos en el terreno de la moralidad. ${ }^{32}$ Los primeros principios y los bienes básicos son premorales, y la moralidad aparecerá "cuando el hombre con su razón y su libertad los haya encarnado en sus concretas decisiones y acciones, por eso la mera comprensión de los bienes no

31 Orrego, C., "Estudio preeliminar", LNDN, cit., nota 5, p. 21.

32 Orrego es especialmente claro en este punto al señalar que “...la existencia de elecciones libres de conductas moralmente malas, pero de todos modos dirigidas por una cierta forma - disminuida, parcial y desordenada- de racionalidad práctica, exige distinguir entre los primeros principios de la razón práctica en general y su correcta o razonable aplicación en la elección del bien moral. El bien moral es el bien propio de la acción libre cuando está conforme con todas las exigencias de la razonabilidad práctica. El mal moral se da en la acción libre cuando no se ordena según las exigencias de la razonabilidad práctica, aunque la acción mala de todas maneras apunta hacia algún bien humano (sólo el bien puede ser objeto del acto de la voluntad), básico o incluso meramente sensible o infrarracional”. Ibidem, pp. 21 y 22 . 
garantiza que ellos sean buscados correcta, adecuada o razonablemente". 33

Los bienes humanos básicos que ofrece Finnis en el orden que él los expone en LNDN son los siguientes: i) la vida, ii) el conocimiento de la verdad, iii) el juego, iv) la experiencia estética, $v$ ) la sociabilidad o amistad, vi) la razonabilidad práctica (referida a la capacidad de decisión en los actos con trascendencia ética), vii) la religión. ${ }^{34}$ Tales bienes son premorales "por cuanto entiende que cada ser humano ya tiene parte en ellos aún antes de toda decisión deliberada de perseguirlos". 35

Las características en tanto que bienes humanos básicos serian las siguientes: i) autoevidentes, o sea, indemostrables en tanto que no necesitan demostración, ii) autónomos, es decir, no hay bienes que sean instrumentos de otros, iii) no hay entre ellos jerarquía alguna, a pesar de que cada persona pueda dar más importancia a unos y a otros. De este modo, un médico protegería más el bien de la vida que el juego. ${ }^{36}$

Establecido el carácter premoral de los bienes básicos, Finnis entiende que la moralidad consiste precisamente en buscar su realización siguiendo o respetando las exigencias de la razonabilidad práctica. Tales exigencias distinguen el pensamiento correcto del incorrecto. Así, establecen "los

33 Vigo, R., L., El iusnaturalismo actual. De M. Villey a J. Finnis, México, Fontamara, 2003, p. 115.

34 Esta nómina de bienes no es una lista en la que éstos se agoten, ni tampoco es la enumeración definitiva en el pensamiento de Finnis. En trabajos posteriores el propio Finnis ha cambiado la enumeración de los bienes. Para esta evolución del pensamiento de John Finnis $c f r$. Orrego, C., "Estudio preeliminar", LNDN, cit., nota 5 , pp. 26-28.

35 Andorno, R., "El paso del "ser" al "deber ser" en el pensamiento iusfilosófico de John Finnis”, Persona y Derecho, 34, Pamplona, 1996, p. 27.

36 "Más importante que la descripción y el número preciso de estos valores es el sentido en que cada uno es básico. En primer lugar, cada uno es una forma de bien igualmente evidente. En segundo lugar, ninguno puede ser reducido analíticamente a ser sólo un aspecto de alguno de los otros, o a ser meramente instrumental en la búsqueda de cualquiera de los otros. En tercer lugar, cada uno, cuando nos concentramos en él, puede razonablemente ser considerado como el más importante. De ahí que no hay una jerarquía objetiva entre ellos". LNDN, cit., nota 5, p. 123. 
criterios para distinguir entre los actos que son razonables... y actos que son irrazonables... entre modos de obrar que son moralmente rectos o moralmente desviados". ${ }^{37} \mathrm{La}$ inteligencia humana discierne lo que es bueno y debe ser perseguido, obrando de una manera diferente a como lo hace con el conocimiento especulativo o metafísico, pero no por eso menos racional que éste. Movida la naturaleza humana por sus inclinaciones, la razón humana por un acto de comprensión capta que el objeto de tal inclinación es una forma general de bien "para uno mismo (y para otros semejantes a uno)", 38 pudiendo establecer cursos de acción, o tomar decisiones, guiados por los requerimientos de la razón práctica.

\section{Los ARGumentos De Mauricio Beuchot}

Expuestos los argumentos centrales de John Finnis, a propósito de la inderivabilidad del "debe" a partir del "es", paso ahora a explicar los reseñados por Mauricio Beuchot. Filósofo mexicano que inscrito en la tradición del derecho natural y del neoescolasticismo ha señalado siempre la dificultad para que la tan temida falacia naturalista pueda alcanzar al derecho natural aristotélico-tomista.

\section{Inexistencia de la falacia naturalista}

En primer lugar, Beuchot, como toda la tradición en la que él se inscribe, acepta que existen diferencias importantes entre los planteamientos de Hume y Moore. Sin embargo, entiende que el argumento central de ambas propuestas

37 Ibidem, p. 57.

38 Ibidem, p. 68. Un ejemplo clarísimo expuesto por Finnis es el de conocimiento. "Uno no juzga que "yo tengo [o todos tienen] una inclinación a aprender sobre las cosas" y entonces infiere por ende "el conocimiento es un bien que ha de ser perseguido". Más bien, por un simple acto de comprensión no inferencial uno capta que el objeto de la inclinación que uno experimenta es un caso de una forma general de bien, para uno mismo (y para otros semejantes a uno)". Idem. 
es el mismo. Quizá ésta sea la razón de no estudiar los razonamientos de ambas posturas en forma separada como lo han hecho otros autores ${ }^{39}$ sino de manera conjunta.

La importancia de los argumentos de Mauricio Beuchot radican fundamentalmente en haber estudiado la problemática de la falacia naturalista desde diferentes ámbitos, algunos coincidentes con los propios de su tradición, y otros distintos a los que ésta defiende, siendo por tanto uno de los teóricos más originales en la crítica a la falacia naturalista. Las ideas que desarrolla para oponerse a la falacia han sido expuestas a lo largo de todo su trabajo intelectual, pero reforzadas y ampliadas en sus publicaciones de la década de los noventa. En primer lugar, se citará Filosofía y derechos humanos, ${ }^{40}$ libro donde Beuchot se ocupará con un poco más de detenimiento de la cuestión debatida. En este trabajo Beuchot niega tajantemente que la falacia naturalista sea aceptable, es decir, se opone radicalmente a que haya un paso ilegítimo del "ser" al "deber-ser". Para esto, elige dos caminos: por una parte, emplea los argumentos de Ulises Moulines ${ }^{41}$, y, por la otra, sugiere el reseñado por Finnis, explicado con anterioridad.

Una vez reconocidos los significativos avances logrados en la filosofia de la ciencia por lo que a los problemas de los términos teóricos y los términos observacionales se refiere, Beuchot advierte, como el propio Moulines lo había señalado, que sin duda hay una distinción real entre el "ser" y el "deber ser", pero igualmente reconoce que tal distinción no es tan tajante ni tan radical como se ha pensado y propuesto. En el mundo físico se acepta que así como se ve en el experimento una importante carga teórica (sin ella sería imposible llevarlo a efecto), así también no hay términos observacionales o experimentales que no estén impregnados

39 Cfr. Massini Correas, C. I., La falacia de la falacia naturalista, Mendoza, Idearium, 1995, passim.

40 Beuchot, M., Filosofía y derechos humanos, México, Siglo XXI, 1993.

41 Para este argumento Beuchot utiliza el trabajo de Moulines, U., "Hechos y valores: falacias y metafalacias. Un ejercicio integracionista", Isegoria, 3, Madrid, 1991. 
de teoría. Aceptar esto nos conduciría a admitir que no hay términos teóricos que se encuentren exentos de un origen empírico, es decir, observacional. De manera semejante, no hay términos descriptivos que estén exentos de valoración, como tampoco hay términos valorativos que no encuentran su base en la experiencia de los hechos. ${ }^{42}$ De este modo, resulta que pasar del "ser" al "deber ser", o del hecho al valor, es algo que se hace continuamente y eso hace que se deje de ver como un paso indebido o falaz. ${ }^{43}$

\section{El recurso al silogismo práctico}

El otro camino que hace suyo Beuchot para oponerse a la falacia naturalista es el expuesto por Finnis, el cual, como vimos, acepta la inderivabilidad del "deber ser" a partir del "ser", pero expresamente señala que Tomás de Aquino (antes Aristóteles) no incurrió en ese error lógico porque conoció perfectamente la distinción entre razonamiento especulativo y práctico, y cómo cada uno de ellos parte de los primeros principios, autoevidentes e indemostrables, no hay ninguna inferencia ilicita. Ubicado por tanto en el razonamiento práctico, más precisamente en el silogismo práctico, el que como todos sabemos es distinto del teórico, ${ }^{44}$ Beuchot se remitirá a la estructura de tal silogismo práctico, para hacer ver que en éste, la primera de las premisas contiene expresamente reconocida la finalidad que uno se propone realizar, los fines que se plantea alcanzar. En la

42 Cfr. Beuchot, M., op. cit., nota 40, p. 136.

43 Es especialmente significativa la siguiente cita de Moulines reproducida por Beuchot: "Superemos la metafalacia dicotomista. No le tengamos tanto miedo a la falacia naturalista ni, por cierto, tampoco a la moralista. En muchos casos, estas formas de razonamiento son realmente improcedentes y es conveniente evitarlas; pero en otros muchos casos no es así. No se encontrará un algoritmo universalmente aplicable para decidir cuándo un paso del "ser" al "deber ser" es realmente falaz, y cuando no. No hay tales algoritmos, sólo hay casuística”. Ibidem, p. 137.

44 “...las proposiciones normativas son proposiciones de la razón práctica; por lo tanto, no se derivan de las proposiciones descriptivas de la razón teórica. Ciertamente, las normas éticas y jurídicas dependen de la naturaleza del hombre, conocida y descrita por la razón teórica; pero no en un sentido lógico de derivación”. Ibidem, pp. 137 y 138. 
segunda de tales premisas se establecen los medios con los que se cuenta para alcanzar el fin propuesto, y, en la conclusión, resulta la línea de acción a tomar para realizar lo que uno se ha propuesto.

Un ejemplo de lo anterior podría ser el siguiente:

P.1. Todo lo que conduce a la paz en la sociedad debe lograrse.

P. 2. Para alcanzar esa paz social es necesaria la justicia.

P. 3. Luego la justicia debe lograrse en nuestra sociedad.

Como se puede ver, en P.1 y P.2, ya se encuentran elementos valorativos, no sólo descriptivos (lo que se requiere para ordenar la sociedad en la justicia y en la paz), pues hay valoración hacia esos bienes que nos conducen a la armonía social, con lo cual, no hay ningún paso indebido del "ser" al "deber ser".

Por tanto, si nos situamos en el puro silogismo práctico, como lo hace Beuchot, no hay razones para aceptar que se esté incurriendo en falacia alguna. Ahora bien, ¿cuál sería el principio del que partiría nuestra argumentación? El mismo Beuchot, tomándolo de Tomás de Aquino, explicará que el primer principio de dicho razonamiento es "El bien hay que hacerlo y el mal evitarlo". El contenido de este principio se concreta sucesivamente a través de las inclinaciones naturales, es decir, de los bienes a alcanzar para el hombre. De modo que de ahí cabe obtener cuáles son los derechos de las personas sin incurrir en falacia alguna. ${ }^{45}$

En efecto, el primer principio de la argumentación práctica y los enunciados de las inclinaciones naturales son descriptivos. Sin embargo, ya hay entonces una premisa práctica y teórica, por lo que se puede inferir una conclusión práctica o valorativa. No hay aquí ninguna inderivabilidad del "debe" del "es".

Aun dentro del razonamiento práctico, Beuchot va un poco más allá, no quedándose sólo en lo que respecta al si-

45 Cfr. ibidem, p. 139. En este punto, Beuchot coincide con Finnis, Kalinowski, Massini y Goméz-Lobo. De éste último $c f r$. "La fundamentación de la ética aristotélica", Anuario Filosófico, XXXII/ 1, Pamplona, 1999, pp. 17-37. 
logismo y a las proposiciones que lo componen, sino colocándose en los términos que integran las proposiciones mismas. Aquí, hace ver que en los propios términos presentes en las oraciones que se usan, hay ya una carga valorativa. El argumento lo toma de Searle que sostiene que los vocablos usados para describir contienen muchas veces elementos que los hacen también valorar. De enunciados descriptivos se obtiene, por transformación, enunciados valorativos, tematizando los componentes axiológicos que pretendian ser solamente descriptivos. ${ }^{46}$

3. En el silogismo teórico tampoco hay alguna falacia ilegitima

Preocupado por la vinculación entre el razonamiento especulativo y el práctico, Beuchot intenta hacer ver que si bien el análisis del silogismo práctico le bastaría para salir de la acusación de la falacia, piensa que incluso en el silogismo teórico no se incurriría tampoco en ésta. Para el profesor mexicano, en la consideración ontológica de la naturaleza humana se encuentran ya las raíces de sus exigencias morales, no a nivel metafísico, pero sí a nivel antropológico-filosófico, o de filosofia del hombre, pues explica que en las necesidades del hombre están ya sus derechos, esto es, lo que nosotros entendemos como derechos humanos, pues la necesidad engendra derechos. ${ }^{47}$

4. Respuesta de la filosofía pragmática para impugnar la falacia naturalista

En otro de sus trabajos, Derechos Humanos, iuspositivismo y iusnaturalismo, ${ }^{48}$ y siguiendo la línea trazada por la fi-

46 Cfr., . Beuchot, M., op. cit., nota 40, p. 141.

47 Cfr. ibidem, pp. 143-145.

48 Beuchot, M., Derechos Humanos iuspositivismo y iusnaturalismo, UNAM, México, 1995. 
losofia pragmatista norteamericana, entre otros por Charles Sanders Peirce, sostiene que la dicotomía entre "es" y "deber ser" o entre hecho y valor, no es tan radical como generalmente es presentada. Muestra que el lenguaje descriptivo no siempre es neutro de valoración, sino que muchas veces encierra elementos valorativos, pues cuando describimos un hecho estamos implicando una valoración, sea con una implicación fuerte, o por lo menos con la implicatura conversacional.

Beuchot utiliza ejemplos de Hilary Putnam, ${ }^{49}$ entre los que se encuentra el del judío sobreviviente de los campos de concentración nazis que narra el infierno que vivió alli, y, por supuesto, no puede estar exento de valoración lo que relata. Utiliza también otros casos que nos muestran que en los vocablos o discursos descriptivos se dan elementos valorativos, y que al pasar del hecho al valor, sólo se explicitan o tematizan, como por ejemplo: "X babeó la comida" no deja de tener un contexto de repulsión hacia tal comportamiento, $\mathrm{y}$ por tanto en tal enunciado descripción y valoración se encuentran. 50

En este trabajo Beuchot refuerza los argumentos de Putnam en tres puntos:

(1) Niega que el paso de lo fáctico a lo axiológico sea una inferencia formal. Es más bien de tipo trascendental.

49 Putnam, H., "Beyond the Fac.-value dicotomy", Critica, XIV/41. Cfr. Tb., "La objetividad y la distinción ciencia/ética", Diánoia, 34, 1988; cfr. tb., "Hecho y valor", Razón, verdad e historia, Tecnos Madrid, 1988.

50 En el caso incluso del discurso científico del positivismo, se encuentran introducidos valores en forma necesaria. Recurriendo al mismo "Putnam aseverará que, si la coherencia y la simplicidad son valores, y si negar que son objetivos es caer en un subjetivismo autorrefutante, entonces se han bloqueado los argumentos clásicos contra la objetividad de los valores éticos. En efecto, si los valores éticos son subjetivos, los valores cognitivos — que están tan aparejados a ellos-igualmente lo son. Al igual que muchos conceptos científicos, están sujetos a la vaguedad; si los valores morales son vagos y sin criterios ni reglas claras, no lo son más que los valores cognitivos o epistemológicos". Crf. Beuchot, M., op. cit., nota 48, p. 147. En esto ha insistido también, como argumento crítico contra el positivismo, Serna, P., "Sobre las respuestas al positivismo jurídico", Rabi-Baldi, R., (ed.) Las razones del derecho natural, Buenos Aires, Ábaco, 2000, cap. I 
(2) Aceptando que sea una inferencia formal, ésta no sería de tipo deductivo, sino inductivo, como el que se da en el paso de lo empírico a lo teórico, "en el sentido de que en lo empírico hay contenidos teóricos que se explicitan en la inducción". ${ }^{51}$

(3) Aceptando que sea una inferencia formal y deductiva, no se estaría "sacando en la conclusión algo que no estaba en las premisas, ya que en las premisas o enunciados fácticos hay una carga axiológica". ${ }^{52}$ Este sería el caso del silogismo práctico, ya expuesto anteriormente.

Finalmente, en el libro Derechos humanos y naturaleza humana, ${ }^{53}$ Beuchot intenta mostrar que, siendo la falacia naturalista uno de los argumentos básicos para sostener la radical separación entre el derecho y la moral, ésta puede ser impugnada analizando el silogismo teórico y sus condiciones. Beuchot piensa que tampoco en este silogismo se comenta falacia alguna, y que por tanto el paso del "ser" al "deber ser" es plenamente legitimo. Esto puede mostrarse utilizando factores modales en las proposiciones, esto es, para designar hechos, modalidades aléticas (necesario, posible, imposible) o epistémicas; para designar valoraciones, modalidades deónticas (permitido, prohibido, mandado). Y, si en la primera premisa se tienen modalidades aléticas o epistémicas, y en la segunda se introducen modalidades deónticas, tiene que obtenerse en la conclusión algo deóntico, pues hay una regla silogística que establece que la conclusión siempre sigue a la parte más débil, y aquí lo deóntico es más débil, epistemológicamente, que lo alético; la conclusión entonces debe ser valorativa. Existiendo aquí una especie de transformación del silogismo teórico en práctico que permite pasar del "ser" al "deber ser" sin cometer ningún error lógico.

51 Beuchot, M., op. cit., nota 48, p. 151.

52 Idem.

53 Beuchot, M., y Saldaña, J., Derechos humanos y naturaleza humana, México, UNAM, 2000, pp. 26-47. 


\section{Recapitulación de la tesis de M. Beuchot}

Primero. Como se ha podido evidenciar, Mauricio Beuchot sigue diferentes caminos para oponerse a la falacia naturalista. Uno de éstos es declararla radicalmente inexistente.

Segundo. Otro de ellos es aceptar, como lo haría Grisez y Finnis, que dicha falacia existe y es verdadera; sin embargo, advierte también que el derecho natural clásico de corte aristotélico-tomista no incurre en ésta al situarse al nivel del silogismo práctico, ya que en este particular tipo de silogismo siempre existirá una premisa con carácter deóntico y la conclusión será necesariamente valorativa.

Tercero. Un tercer camino propuesto por Beuchot es abordar el problema desde la perspectiva del silogismo teórico, haciendo ver que si en este silogismo se introducen valoraciones, en alguna de las premisas, tiene que concluirse algo valorativo, pues lo deóntico es más débil que lo veritativo y epistémico, y la conclusión sigue a la parte más débil.

Cuarto. Finalmente, utiliza el análisis de los términos que se emplean en el supuesto paso falaz para mostrar que en su misma constitución semántico-pragmática tiene aspectos valorativos que solamente se explicitan o se hacen temáticos.

Como filósofo analítico, Beuchot ha empleado algunos de los recursos más significativos para oponerse a la falacia naturalista. Con los argumentos de Beuchot se confirma la tesis de que el análisis filosófico y la explicación aristotelica-tomista del derecho natural no son, ni por mucho, posturas necesariamente antagónicas. Lo anterior nos permite afirmar que las distintas respuestas que se han dado, tanto al paralogismo lógico de Hume, como a la falacia naturalista de Moore por parte del iusnaturalismo clásico, no sólo podrian provenir de un argumento metafísico (recuérdese que uno de los trascendentales de "ser" es la bondad), o de la estructura del silogismo práctico, sino incluso también desde las propias herramientas de la filosofia analitica o pragmática contemporánea. De este modo y ante aplastan- 
tes argumentos, será muy difícil seguir sosteniendo con rigurosidad que una teoría iusnaturalista, o aquella otra basada en un cognitivismo moral objetivo, sea incapaz de superar el desafio de la tan temida falacia naturalista.

\section{CONCLUSIÓN}

Llegados a este punto creo que es necesario señalar como comentario conclusivo que después de la exposición de algunos de los más importantes argumentos utilizados por John Finnis y Mauricio Beuchot para oponerse a la temida falacia naturalista, será muy difícil seguir atacando cualquier ética de carácter objetiva, y, por supuesto, continuar objetando las tesis centrales del derecho natural, al menos el derecho que echa raíces en Aristóteles y Tomás de Aquino. Estos pensadores y el derecho que ellos defendieron se encuentra muy lejos de incurrir en tal error lógico, antes bien, conocieron perfectamente la diferenciación entre razonamiento especulativo y práctico. Estamos entonces en condiciones de seguir pensando y argumentando a favor del derecho natural.

\section{BIBLIOGRAFÍA}

AQuino, Tomas De, Summa Theologiae, I-II, q, 94. a. 2., Madrid, BAC, 1997.

Hume, D., Treatise of Human Nature, L.A., Selby-Bigge, M. A., Oxford, reprinted, 1960.

ANDORNO, R., "El paso del "ser" al "deber ser" en el pensamiento iusfilosófico de John Finnis", Persona y Derecho, 34, Pamplona, 1996.

Beuchot, M., Filosofía y derechos humanos, México, Siglo XXI, 1993.

- Derechos humanos, iuspositivismo y iusnaturalismo, México, UNAM, 1995. 
Beuchot, M. y SAldAÑA, J., Derechos humanos y naturaleza humana, México, UNAM, 2000.

ERRÁZURIZ MACKENNA, C., J., La teoría pura del derecho de Hans Kelsen. Una visión crítica, Pamplona, Eunsa, 1986.

FINNIS, J., Natural law and Natural Rights, Oxford, Claredon Press, 1980; traducción al castellano de Orrego, C., Ley Natural y derechos naturales, Buenos Aires, Abeledo-Perrot, 2000.

- Fundamentals of Ethics, Londres, Georgetown University Press, 1983.

- "Natural law and the "is"-"ought" question: an invitation to profesor Veatch", The catholic lawyer, 26/4, 1981.

- "Natural inclinations and natural rights: deriving "ought" from "is" according to Aquinas", en ELDERS, L. J. y HEDWIG, K. (eds.), Lex et libertas. Freedom and law according to St. Thomas Aquinas, Citta del Vaticano, Pontificia Academia di S. Tommaso, Libreria Editrice Vaticana, 1987.

GARCíA HUIDOBRO, J., Razón práctica y derecho natural (el iusnaturalismo de Tomás de Aquino), Valparaíso, Edeval, 1993.

GEORGE P., R., In defense of natural law, Gran Bretaña, Oxford, U.P., 2001.

- "Ley natural y naturaleza humana", Boletín Mexicano de Derecho Comparado, 110, México, 2004.

GomÉz-LoBO, A., "La fundamentación de la ética aristotélica”, Anuario Filosófico, XXXII/ 1, Pamplona, 1999.

Kelsen, H., Teoría pura del derecho, México, Porrúa-UNAM, 1991.

MAcInTYRE, A., Justicia y racionalidad, 2a. ed., trad. cast. A. J., Sison, Pamplona, Eiunsa, 2001.

MASSINI CORREAS, C. I., La falacia de la falacia naturalista, Mendoza, Idearium, 1995. 
- "The new school of natural law. Some approaches", Rechtstheorie, 30, Berlin, 1999.

—_, "Razón práctica y objetividad del derecho. El debate contemporáneo acerca de los principios jurídicos", Sapientia, LIX., fas. 215, Buenos Aires, 2004.

MOULINES, U., "Hechos y valores: falacias y metafalacias. Un ejercicio integracionista", Isegoría, 3, Madrid, 1991.

OCARIZ, F., "Rasgos fundamentales del pensamiento de Santo Tomás" en varios autores, Tomás de Aquino también hoy, Pamplona, Eunsa, 1990.

OLLERO, A., ¿Tiene razón el derecho? Entre método científico y voluntad politica, Madrid, Congreso de los Diputados, 1996.

ORREGO SÁNCHEZ, C., "Estudio introductorio", Ley natural y derechos naturales, Buenos Aires, Abeledo-Perrot, 2000.

—_, "Aciertos y certidumbres", Persona y Derecho, 40, Pamplona, 1999.

Putnam, H., "Beyond the Fac.-value dicotomy", Critica, $X I V / 41$.

—, "La objetividad y la distinción ciencia/ética", Dián oia, 34, 1988.

- - "Hecho y valor", Razón, verdad e historia, Madrid, Tecnos, 1988.

SERNA, P., "Hermenéutica y relativismo", De la argumentación a la hermenéutica, Granada, Comares, 2003.

—-, "Sobre las respuestas al positivismo jurídico", en RABÍ-BALDI, R., (ed.), Las razones del derecho natural, Buenos Aires, Ábaco, 2000, cap. I.

SOAJE RAmos, G., "John Finnis y el derecho natural", Anuario de Filosofía Jurídica y Social, 7, Buenos Aires, 1987. 


\section{LA FALACIA NATURALISTA}

—, "Sobre Fundamentals of ethics", Ethos, 14-15, Buenos Aires, 1986.

VEATCH, H., "Natural Law and the Is-Ought Question", Catholic Lawyer, 26, 1981.

Vigo, R., L., El iusnaturalismo actual. De M. Villey a J. Finnis, México, Fontamara, 2003. 